\title{
The ability of crab and cockle shell to adsorb lead and chromium from industrial effluent
}

\author{
Kamsia Budin $^{1}$, Yogeswaran Subramaniam ${ }^{2}$, Rohana Tair ${ }^{1}$ \\ And Siti Aishah Mohd. Ali ${ }^{1}$ \\ ${ }^{\prime}$ (Water Research Unit, Faculty of Science and Natural Resources, UMS, Malaysia) \\ ${ }^{2}$ (Environmental Science Programme, Faculty of Science and Natural Resources, UMS, Malaysia)
}

\begin{abstract}
The ability of crab shell (Scylla serata) and cockle shell (Anadara granosa) to remove $\mathrm{Pb}$, and $\mathrm{Cr}$ from industrial effluent was examined to determine its removal efficiency. This research was conducted under constant $\mathrm{pH}$ around 4 under room temperature and all samples were shacked to $150 \mathrm{rpm}$. Other factors like amount of adsorbent, types of adsorbent and time equilibrium was examined along this research. The highest uptake of heavy metals recorded is by crab shells compare to cockle shells. All heavy metals except chromium reached equilibrium after 60 minutes time. The most of heavy metals was adsorbed by amount of $1.0 \mathrm{~g}$ compare to other amount of adsorbent $(0.5 \mathrm{~g}$ and $1.0 \mathrm{~g})$. The amount of adsorbent and type of adsorbent were strongly correlated by amount of heavy metals adsorption. $(p<0.001)$. Chromium was the highest heavy metals that were removed in industrial effluent. The highest reading was recorded as $97.45 \% . \mathrm{CaCO}_{3}$ and chitin play an important role to adsorb heavy metals in industrial effluent. Although, there are many other particles existed in industrial effluent but still crab shells and cockles can be used as biomass adsorbent to remove heavy metals in industrial effluent.
\end{abstract}

Keywords: Lead, chromium, crab shell, cockle shell, adsorbent, industrial effluent

\section{Introduction}

One of the major sources of water pollution in Malaysia is discharges from industries. Normally, the effluent from industries is polluted by organic matter, microorganism and other sources according to industry type. In this case, discharging heavy metals become worse than other environmental problems. It is historically been problematic due to inability to comply with environmental and waste disposal regulation. At the moment, many technologies were used to treat heavy metals in industrial effluent includes reverse osmosis, ion exchange, electrolysis and membrane filtering. But most this technologies are costly and sometimes can be too technical.

Bio-adsorption is a new technology that efficiently removes heavy metals from industrial effluent. Basically, alga, resin and plant were used to remove heavy metals in industrial effluent. In this case, crabs and cockle shells were use as adsorbent. According to [1][2], both has high capacity of heavy metals adsorption with low cost operation, simple and yet effective.

\section{Materials And Methods}

Crab shell of Scylla serata and cockles shell of Anadara granosa were obtained as wastes from around the shores along the coast of Kota Kinabalu in Sabah, Malaysia. The shells were separated from their meat by steaming or boiling, washed and then dried without any special treatment. They were then pulverized to a geometric mean particle size of $0.5 \mathrm{~mm}$ and separate into three different amount; $0.25 \mathrm{~g}, 0.5 \mathrm{~g}$ and $1.0 \mathrm{~g}$.

The adsorption experiment were conducted under $\mathrm{pH} 5.0$ and room temperature with $150 \mathrm{rpm}$ shaking condition to study the effects of mass adsorbents $(0.25 \mathrm{~g}, 0.5 \mathrm{~g}$ and $1.0 \mathrm{~g})$ and time of exposure at $5,30,60,180$, 360 , and 540 minutes. The $\mathrm{Pb}$ and $\mathrm{Cr}$ concentrations in the supernatant were analyzed by flame absorption spectrophotometer (AAS Polarized Zeeman Z- 5000) and the percentage removal efficiency was determined as follows:

$$
\% C=\frac{C_{o}-C_{t}}{C_{o}} \times 100
$$

Where $\mathrm{Co}$ is the initial concentration of $\mathrm{Pb}$ and $\mathrm{Cr}(\mathrm{mg} / \mathrm{l}), \mathrm{C}_{\mathrm{t}}$ is the concentration $(\mathrm{mg} / \mathrm{l})$ of $\mathrm{Pb}$ and $\mathrm{Cr}$ in the aqueous in $t$ minutes [2][3].

A $1500 \mathrm{ml}$ of industrial effluent was collected from electric and electronic manufacturing factories. The characteristic of the effluent such as temperature, $\mathrm{pH}$, Electro conductivity, the concentration of $\mathrm{Pb}$ and $\mathrm{Cr}$ and light metals $(\mathrm{Na}, \mathrm{K}, \mathrm{Cl})$ were determined and used as the initial criteria for the metal removal efficiency analysis. Afterwards, the both segregated sample (crab shell and cockle shell) were added into $250 \mathrm{ml}$ industrial effluent. Later on, $10 \mathrm{ml}$ samples were collected and filtered for 5, 30, 60, 180, 360 and 540 minutes. The final concentration of heavy metals were analized using Atomic Adsorption Spectrofotometer (AAS). 


\section{Result}

Based on result, chromium (figure 1a, $1 \mathrm{~b}$ and $1 \mathrm{c}$ ) indicate high ability of removal by both crab shells and cockle shells. Lead (figure $2 \mathrm{a}, 2 \mathrm{~b}$ and $2 \mathrm{c}$ ) was removed as second metals remove by both absorbent. The crab shell has better capability to remove both heavy metals compare to cockle shell. The absorbent $1.0 \mathrm{~g}$ has high ability of adsorbed heavy metals compare to $0.5 \mathrm{~g}$ and $0.25 \mathrm{~g}$. The amount of adsorbent and type of adsorbent were strongly correlated by amount of heavy metals adsorption. $(\mathrm{p}<0.001)$. Chromium was the highest heavy metals that were removed in industrial effluent. The highest reading was recorded as $97.45 \%$. Time between 0 to 60 minute is duration of time where the adsorption occur maximum range for both heavy metals.
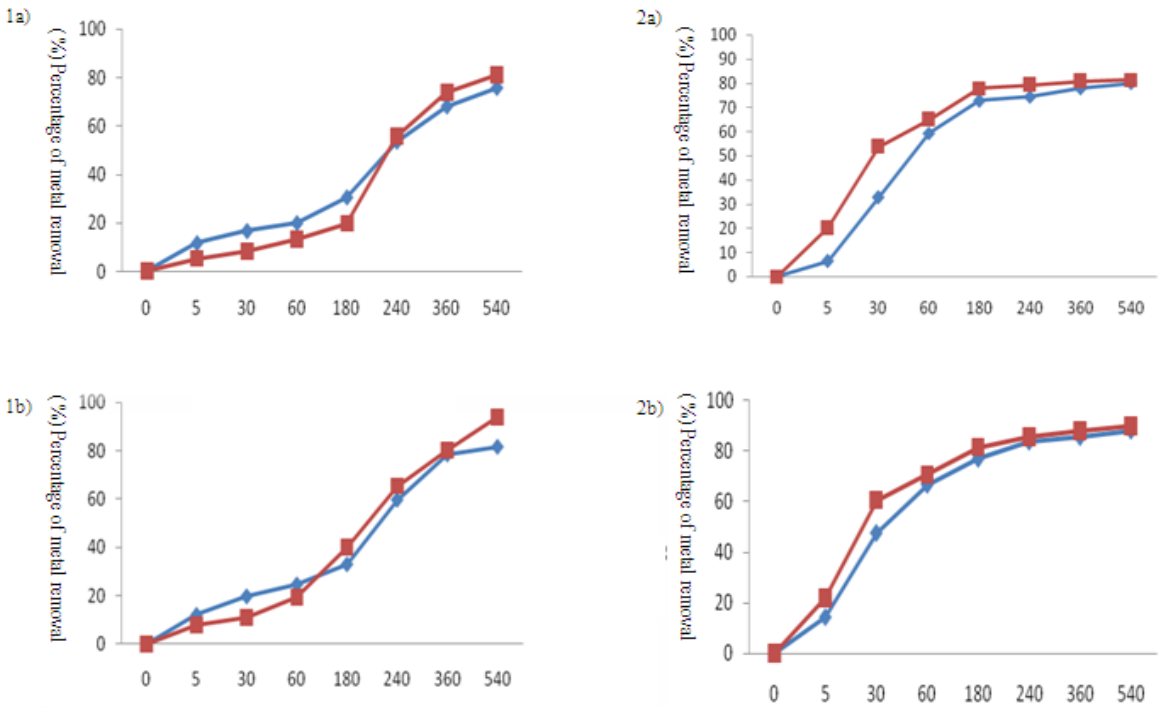

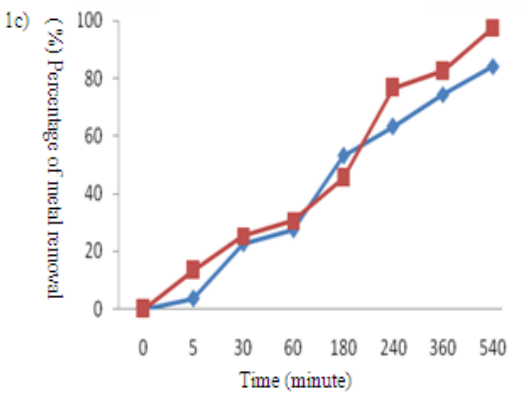

Figure l: Percentage of chromium metals removal by a) $0.25 \mathrm{~g}$ b) $0.5 \mathrm{~g}$ and c) $1.0 \mathrm{~g}$ adsorbent.

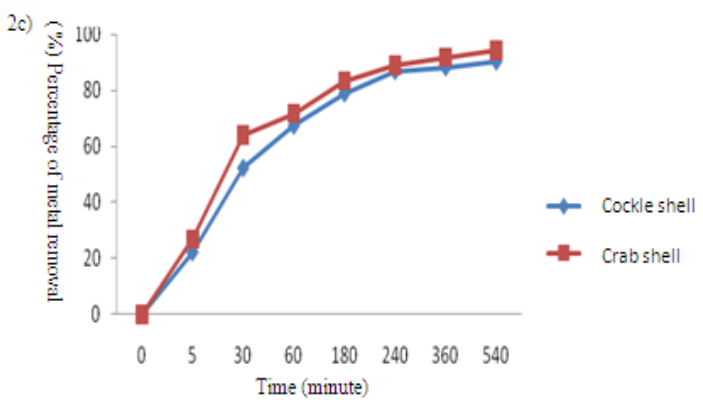

Figure 2: Percentage of plumbum metals removal by a a) $0.25 \mathrm{~g}$ b) $0.5 \mathrm{~g}$ and c) $1.0 \mathrm{~g}$ adsorbent.

\section{Discussion}

There are many factors affecting on this bio-adsorption process includes mass of adsorbent, effect of shaking, type of adsorbent used, and present of other suspended solids in industrial effluent. Normally, crab shells have high potential to remove heavy metals in industrial effluent compare to cockle shells. Extra structure chitin and high composition of $\mathrm{CaCO}_{3}$ make crab shells lead to adsorb heavy metals in industrial effluent.

In fact, chitin is formation of $\left(\mathrm{NH}_{2}{ }^{-}\right)$molecule that adsorb positive ion of heavy metals industrial effluent. These structures of chitin provide strong stability and high reacting forces to crab shells to remove heavy metals in industrial effluent [4][5]. However, cockle removes heavy metals by using only $\mathrm{CaCO}_{3}$ structures. The process of removing all heavy metals by structure of $\mathrm{CaCO}_{3}$ is called as ion exchange.

Usually, high volume of adsorbent has big ability of removing heavy metals in industrial effluent. High volume of adsorbent provide large amount of surface area to heavy metals in industrial effluent [2]. Still, highest volume of adsorbent $(<1.5 \mathrm{~g})$ can agitate or reduce ion binding between heavy metals and adsorbent. As a result, $1.0 \mathrm{~g}$ adsorbent is exceptional quantity to remove heavy metals in $250 \mathrm{ml}$ industrial effluent. 
The effect of shaking also influences the process of adsorption. Studied by [6][7], the result of removing heavy metals increases by process of shaking. Because the shaking process enhance heavy metals bind with adsorbent pore. Usually, the open pore of adsorbent (crab shell and cockle shell) easy to capture heavy metals when the industrial solution was in shivering stages [6].

\section{Conclusion}

According to this research, crabs shells have high ability of adsorbing heavy metals compare to cockle shells. The $1.0 \mathrm{~g}$ amount of absorbent has high capacity of removal heavy metals in industrial effluent compare to $0.5 \mathrm{~g}$ and $0.25 \mathrm{~g}$. Chromium is the highest metals that removed in industrial effluent compare to Pb. Further study needed on the existence of other particle like chloride and light metals in industrial effluent. As in reality, this type of particle can break heavy metals binding with crab shells and cockle shells.

\section{References}

[1] M.Y. Lee, J.M Park, and J.W. Yang. Micro precipitation of lead on the surface of crab shell particles, Process Biochemistry, 32, 1997, 671-677.

[2] Kim, D.S., $\mathrm{Pb}^{2+}$ removal from aqueous solution using crab shell treated by acid and alkali. Bioresource Technology, 94 (3), 2004 , 345-348.

[3] Kamsia, B., Abdullah, H., Siti Rohayu Mohd. Hashim dan Abdullah, N., Removal of lead(Pb) from aqueous solution using crab (Portunus pelagicus) and (Anadara granosa) shell waste. Proceedings of the $2^{\text {nd }}$ SANREM Conference, 2006.

[4] Chu, K.H., Removal of Copper from aqueous solution by chitosan in prawn shell: Adsorption Equilibrium and Kinetics. Journal of Hazardous Materials, 90, 2002, 77-95.

[5] Vijayaraghavan, K. Palanivelu, K. Velan, M., Crab shell-based biosorption technology for treatment of nickel-bearing electroplating industrial effluents. Journal of Hazardous, 119, 2005, 251-254.

[6] An, H.K., Park, B.Y. and Kim, D.S., Crab shell for removal of heavy metals from aqueous. Water Research, 35 (15), 2001, 3551 3556 .

[7] Vijayaraghavan, K., Jegan, K. Palanivelu, K and Velan, M., 2004. Biosorption of Copper(II) and cobalt(II) from aqueous solution by crab shell particles. Bioresource Technology. 97(12), 411-1419. 